
\title{
28 Research Square \\ The effect of joint pain and arthritis on the Montana ranching and farming community
}

\section{Eliza J Webber}

Montana State University

Tan Tran

Montana State University

Ronald June

Montana State University

Emily Healy

Montana Department of Labor and Industry

\section{Tara M Andrews}

Montana State University

Roubie Younkin

Montana State University

Justin MacDonald

University of Washington School of Medicine

Erik S Adams ( $\square$ erik.adams@montana.edu )

Montana State University https://orcid.org/0000-0002-7625-0829

\section{Research article}

Keywords:

Posted Date: February 18th, 2020

DOI: https://doi.org/10.21203/rs.2.23826/v1

License: (c) (1) This work is licensed under a Creative Commons Attribution 4.0 International License.

Read Full License 


\section{Abstract}

Background: Arthritis and joint pain have shown high prevalence rates in agricultural workers and is of concern because many agricultural operations are sustained by a small number of workers. The disability of even one worker may therefore contribute to economic hardship. This study investigated joint health in Montana agricultural workers and its economic effects on ranches and farms. Methods: The aims of this study were to determine associations between years working in agriculture and joint health, and between joint health and the economic health of a ranch or farm. A total of 299 ranchers and farmers in nine Montana counties completed a survey that included an assessment of the economic health of the ranch or farm, work capacity, and the need to rely on others to complete one's work. Focus groups were then held with ranchers in two Montana counties, discussing similar topics. Results: $87.6 \%$ of survey respondents reported joint pain, $47.8 \%$ a diagnosis of arthritis, and $22.4 \%$ osteoarthritis (OA). Using proportional odds regression analysis, a 10-point increase in the Western Ontario and McMaster University arthritis index (WOMAC) score was significantly associated with lower work capacity (OR 2.00; $95 \% \mathrm{Cl}[1.58,2.55], \mathrm{p}<0.01)$, worse financial condition (OR 1.23; 95\% Cl [1.01,1.48], $\mathrm{p}=0.04$ ), and increased reliance on others (OR 1.82; $95 \% \mathrm{Cl}[1.32,2.55], \mathrm{p}<0.01)$. A diagnosis of arthritis was associated with moving to a worse category of work capacity (OR 4.66; 95\% $\mathrm{Cl}[2.71,8.01], \mathrm{p}<0.01)$ and increased odds of relying on others (OR $3.23 ; 95 \% \mathrm{Cl}[1.56,6.66], \mathrm{p}<0.01)$, compared to those without arthritis. A diagnosis of OA was significantly associated with decreased work capacity (OR 3.47; 95\% $\mathrm{Cl}[1.97,6.11], \mathrm{p}<0.01$ ). Adjusting for age and BMI, we found no association between years spent working in agriculture and joint health. Focus group themes included decreased productivity with increased joint symptoms and a tendency for ranchers to avoid interaction with the health care system. Conclusions: This mixed-methods study demonstrated an association between poor joint health and economic risk on Montana ranches and farms.

\section{Introduction}

Arthritis is a leading cause of work limitations (1-3) that affected over 54 million individuals in the United States between 2013 and 2015.(4) Approximately half of those with arthritis experience disability.(4). Farmers and ranchers have been shown to have higher rates of osteoarthritis than the general population. (5-7) Agriculture is of particular interest in this regard, for multiple reasons: our reliance on their products, the impact of disability on production, and the well-known economic difficulties associated with ranching and farming. Agricultural operations are often small, with family farms having only 1-2 workers and often no hired help,(8) so the physical disability of only one person may have a significant effect.

The etiology behind higher osteoarthritis rates in agricultural workers is unclear. Agriculture is a physically-demanding occupation, and some studies have shown an association between high physical workload and osteoarthritis.(9-12) In a study of hip and knee arthroplasty by occupation, using sedentary occupations as a control group, male farmers had an odds ratio (OR) of 5.1 for knee replacement and 3.6 for hip replacement, higher than four other physically-demanding occupations.(13) Thelin and Holmberg found that farmers had an OR of 3.0 for hip osteoarthritis and 2.1 for osteoarthritis 
at any joint, compared to urban counterparts.(14) A large-scale Swedish study showed that male farmers had the highest relative risk (RR) among high exposure occupations of hospitalization for hip osteoarthritis, at 3.78, compared to low exposure occupations.(12) However, in a study of 90 year old men and women, $10 \%$ of subjects were free of osteoarthritis, with history of heavy physical labor associated with a 7.2 times higher odds of being free of osteoarthritis.(15)

The first aim of this study was to determine associations between years spent working in agriculture and joint health, and our second aim was to investigate the relationship between joint health and the economic well-being of a ranch or farm. These were investigated with a survey of Montana ranchers and farmers ("ag producers"). We also conducted focus groups with Montana ranchers to obtain their viewpoints regarding the effect of joint pain and arthritis on their ability to work, interactions with the health care system, and the economics of agriculture.

\section{Methods}

This study was approved by the Montana State University (MSU) Institutional Review Board, and all participants provided informed consent. We partnered with MSU Extension because of their close ties to the farming and ranching community. MSU Extension has agents and an office in each of 56 Montana counties and 7 Montana reservations that are involved in education and community projects that are both agriculture and non-agriculture related.(16) The survey (Appendix 1) consisted of 42 questions, and survey responses were confidential. Ag producers in all 9 participating counties received email invitations between 3/19/18 and 4/16/18 to complete the survey online, using email lists kept by Extension agents. Study data were collected and managed using REDCap (Research Electronic Data Capture) v8.9.2, hosted at the Institute of Translational Health Sciences, University of Washington. $(17,18)$

REDCap is a secure, web-based software platform designed to support data capture for research studies, providing 1) an intuitive interface for validated data capture; 2 ) audit trails for tracking data manipulation and export procedures; 3 ) automated export procedures for seamless data downloads to common statistical packages; and 4) procedures for data integration and interoperability with external sources.

Paper surveys were mailed to ag producers in Custer County on 4/15/18, as that Extension office's email list was considered incomplete. Extension agents in Granite and Liberty Counties stated that their ag producers tended to respond better to mail, so paper surveys were mailed to producers in those counties on $6 / 8 / 19$ and $7 / 27 / 18$, respectively. Paper surveys were also completed at agricultural events in Valley and Richland Counties in April, 2018. Invitations to complete paper surveys were accompanied by a request to not do so if the recipient had already completed an online survey. Completed paper surveys were mailed to MSU, and their data were manually entered into REDCap.

Survey respondents provided information on their joint pain and arthritis diagnosis status, work limitations caused by joint pain, and economic impacts. Those with hip or knee pain completed a Western Ontario and McMaster University osteoarthritis index (WOMAC). Surveys were excluded from the analysis if the respondent did not answer key questions about whether they had joint pain. Appendix 2 
shows the participating counties. Respondents were sent a \$15 gift card for an online store, in a manner that preserved confidentiality.

\section{Data Analysis}

Survey responses were downloaded from REDCap. Data were then cleaned to remove blank survey submissions (observations containing missing values for $100 \%$ of study variables) and illogical response values. All analyses were conducted using SAS 9.4 (SAS Institute Inc., Cary, NC, United States of America). Descriptive statistics were produced to show overall, unadjusted distribution of study outcomes and population demographics in our sample. Continuous variables were presented as both medians with inter-quartile ranges and means with standard deviations, while categorical variables were presented as numbers and percentages.

In our first aim, we assessed the following joint health outcomes: joint pain (yes/no), arthritis diagnosis (yes/no), osteoarthritis (OA) diagnosis (yes/no) and WOMAC score (continuous). OA diagnosis was extrapolated as a dummy variable from the categorical variable "arthritis type", which included "osteoarthritis", "rheumatoid arthritis", "gout”, "psoriatic", "lupus”, "Lyme arthritis”, "other”, and "not sure”. The primary predictor was years working. Logistic regression modeled the unadjusted and adjusted effect of years working on joint pain, arthritis diagnosis, and OA diagnosis, while general linear regression modeled the effect of years working on WOMAC score, among those with hip or knee pain. Age and body mass index (BMI) were included as covariates in the adjusted models, using the equations given in Appendix 3.

Our second aim was to determine the association between joint health and the following economic risk outcomes: financial well-being of the ranch or farm, workload capacity, and reliance on others to perform one's work. The financial well-being question applied to all respondents, while questions about workload capacity and reliance on others were answered only by those with joint pain. The primary predictor was WOMAC score, among those with hip or knee pain. Presence of an arthritis diagnosis and an OA diagnosis were secondary predictors. Financial well-being categories included "extremely well", "fairly well", "breaking even", and "doing poorly". Workload capacity measured the percentage of work farmers/ranchers with joint pain were still able to perform, compared to their previous capacity. Categories included " $100 \%$ of previous capacity", " $50 \%-75 \%$ of previous capacity", " $25 \%-50 \%$ of previous capacity", "less than $25 \%$ of previous capacity", and "I cannot perform any physical work at all." A category of "75-99\% of previous capacity" was not included, as a distinction was needed between an ability to perform all work (100\%) and the first level of disability (75-99\%). Categories of $<25 \%$ and $0 \%$ were collapsed in all study analyses.

Workload capacity was treated as an ordinal variable, allowing the category of " $100 \%$ " to represent "75\%-100\%" as a complete continuous ordinal response. Proportional odds regression(19) modeled the odds of moving from a category of workload capacity to the next category of doing less work. In the following set of cumulative probability models, the cumulative probability of "farmer/ranchers being able 
to perform at $<25 \%$ or more of their previous work capacity" is not shown because it covers all possible categories and equals 1 . The model controlled for age, years working, and BMI, as shown in Appendix 3.

\section{Sensitivity analyses}

Sensitivity analyses were conducted to assess differences in joint health outcomes and impact of joint health on economic risk, by farming/ranching type. Farming/ranching type was determined by the top two agricultural ("ag") commodities produced on the respondent's farm/ranch. Options included cattle, sheep, dairy, other livestock, small grains/cereal, pulse crops, hay, and other crops. Dairy, other livestock and other crops were not included in the analyses due to small sample size $(\mathrm{N}<15)$. Each commodity was included as a binary predictor in the regression models described in Aim 1 to assess impact on 1) joint pain, 2) arthritis diagnosis 3) osteoarthritis diagnosis and 4) WOMAC score, controlling for age, years working and BMI. Next, Aim 2's models, assessing impact of WOMAC score, arthritis diagnosis and OA diagnosis on economic risk were re-run, stratified by top farming/ranching commodity.

\section{Focus groups}

Focus groups were assembled in Custer and Valley Counties by invitation from the agricultural Extension agents, consisting of 6-7 ranchers per county. Meetings were led by asking the questions shown in Appendix 4, and encouraging participants to share their own experiences and perceptions of the agricultural community. Audio recordings from the meetings were transcribed, and two researchers conducted a formal content analysis of the transcripts. Audio recordings and corresponding transcripts were reviewed in their entirety by each of the researchers. Preliminary themes and representative quotes were independently identified using an inductive "bottom up" approach in which codes were developed from the data. Preliminary themes were then compared and further refined until consensus was reached between the two researchers.

\section{Results}

\section{Survey results}

We received 304 surveys, 213 in paper format. Four were returned with no data, and one with a nonsensical answer to years spent working. These five surveys were deleted. Duplication of a paper survey was detected in one instance, with five surveys returned showing identical data, in identical handwriting; the survey data were entered only once. This left 299 surveys for analysis. For those questions not requiring a conditional previous response (e.g., only if you have joint pain...) missing responses occurred at a mean rate of $2.42(0.81 \%)$ per question (SD 1.92) with number of workers being members of the respondent's family ( $2.01 \%$ missing), weight ( $2.01 \%$ missing), height (1.67\% missing), financial wellbeing of the farm or ranch (1.34\% missing) and number of employees hired (1.34\%) comprising the questions with highest missing response rates. Survey responses by county are shown in Appendix 2, with 
cumulative data by county for a selection of survey questions. Response rates were calculated as number of surveys completed per email address or mailing address invited to participate. In the three counties that received mailed surveys, the mailing list for ag producers contained more producers than the email list and also resulted in a better response rate. In Liberty County, 124 emailed invitations resulted in 6 completed surveys (4.9\%), whereas 192 mailed invitations resulted in 95 (49.4\%), for a total response rate of $52.6 \%$ for Liberty County. The corresponding emailed/mailed response rates for Custer and Granite Counties were $18.9 \% / 34.5 \%$ and $28.6 \% / 50.0 \%$ per email or mailing address, respectively. Among the counties that received only emailed invitations, response rates ranged from $4.3 \%$ to $14.2 \%$. The number of emailed, mailed and in-person (agricultural event) survey invitations, and completed surveys by county are included in Appendix 2.

Out of the 299 survey respondents, $87.6 \%$ experienced joint pain, $47.8 \%$ had been diagnosed with arthritis, and $22.4 \%$ had a diagnosis of OA. Among those with hip and knee pain $(n=123)$, median WOMAC score was 23 (IQR: 13, 34). Median respondent age was 62 (IQR: 54, 68), mean age 59.6 (SD 14.13), median number of years working on farm/ranch was 40 (IQR: 27, 48), mean years working 37.7 (SD 16.4), median BMI was 27 (IQR: 25, 31), and mean BMI 28.2 (SD 4.2). Top produced commodities were cattle (64.6\%), small grains/cereal (40.8\%) and hay (38.5\%). The majority of farmers/ranchers reported doing fairly well $(51.8 \%)$ or extremely well $(11.7 \%)$ financially. Among those with joint pain, $45.8 \%$ reported a reduction in workload capacity, and $27.4 \%$ needed to rely on others to perform previous pre-joint pain duties. (Table 1.)

After adjusting for age and BMI, no evidence of association was observed between number of years working on a farm/ranch and the following joint health outcomes: presence of joint pain (OR 1.00; $95 \% \mathrm{Cl}$ $[0.70,1.42], \mathrm{p}=0.99$ ), arthritis diagnosis (OR 0.99; $95 \% \mathrm{Cl}[0.79,1.24], \mathrm{p}=0.93)$, OA diagnosis (OR 0.83; $95 \% \mathrm{Cl}[0.64,1.07], \mathrm{p}=0.28$ ) and WOMAC score (mean difference: $-0.38 ; 95 \% \mathrm{Cl}[-2.41,1.65], \mathrm{p}=0.71$ ) per 10-unit increase in years working (Table 2 and Figure 1A-C)..

Table 3 demonstrates the associations between WOMAC score, arthritis diagnosis, and OA diagnosis on economic risk outcomes, overall and stratified by top ag commodity. Overall, every 10-point increase in WOMAC score among those with hip or knee pain was associated with double the odds of reporting a next lower work capacity in the survey (OR 2.00; $95 \% \mathrm{Cl}[1.58,2.55], p<0.01)$, significantly higher odds of moving to the next worse financial category (OR 1.23, $95 \% \mathrm{Cl}[1.01,1.48], \mathrm{p}=0.04)$, and significantly higher odds of needing to rely on others to complete farm/ranch duties (OR 1.82, 95\% Cl [1.32, 2.55], $p<0.01)$. The association between higher WOMAC scores and reduced workload capacity remained across all ag commodity types. Associations between WOMAC and other economic risk outcomes were more varied across commodity types. Higher WOMAC scores were significantly associated with needing to rely on others among cattle farmers $(p<0.01)$ small grain/cereal farmers $(p=0.02)$ and hay farmers $(p$ $=0.01$ ), while an association between WOMAC score and self-report of decreased financial well-being was only present in pulse crop farmers $(p=0.02)$. 
Overall, farmers with diagnosed arthritis had a nearly 5 times higher odds of reduced capacity (OR 4.66; $95 \% \mathrm{Cl}[2.71,8.71], \mathrm{p}<0.01)$, and significantly higher odds of needing to rely on others to complete farm/ranch duties (OR 3.23; $95 \% \mathrm{Cl}[1.56,6.66], \mathrm{p}<0.01)$, compared to those without an arthritis diagnosis. Among those with diagnosed OA, an association with diminished work capacity remained (OR 3.47, 95\% $\mathrm{Cl}[1.97,6.11, p<0.01]$, compared to those without, but no significant difference was observed in needing to rely on others. Overall, no difference in financial well-being status was observed between those with and without an arthritis diagnosis (OR $1.02,95 \% \mathrm{Cl}[0.65,1.62], \mathrm{p}=0.92]$ or OA diagnosis (OR $0.83,95 \% \mathrm{Cl}$ $[0.48,1.42], p=0.49)$. When stratified by ag commodity, associations between arthritis and OA diagnosis and diminished work capacity remained in cattle ranchers $(p<0.01)$, small grain/cereal farmers $(p=0.01$ for arthritis, $p=0.02$ for $O A)$ and hay farmers $(p<0.01$ for arthritis and $p=0.01$ for $0 A)$. Having an arthritis diagnosis was positively associated with needing to rely on others among cattle ranchers $(p=0.01)$ and small grain/cereal farmers $(p=0.01)$. An OA diagnosis was associated with higher odds of doing well financially in cattle ranchers $(p=0.01)$. Because of the low number of respondents producing certain commodities (e.g., sheep, pulse crops), stratified analyses are limited in power and data for these commodities should be considered dubious. Still, Table 3 demonstrate that, across all commodities, there is $95 \%$ confidence in the odds of those with hip and knee pain experiencing an increasingly higher odds of moving to the next lower quartile of work capacity with every 10-point increase in WOMAC. Excluding sheep ranchers and pulse crop farmers, similar associations with reduction in work capacity were observed when comparing diagnosis statuses of arthritis and OA, respectively, by commodity type. No other significant associations were observed between joint health and economic risk, stratified by farming/ranching commodity type.

\section{Focus group results}

Two researchers independently identified the following themes and sub-themes: lack of access to healthcare (sub-themes: time pressures, cost, skepticism, cultural value of toughness), younger generation leaving ranching, ranching is a lifelong occupation, and physical demands of ranch work (sub themes: demands of cattle ranching, physical toll on body, technological advances in equipment). Quotes extracted from the focus group transcriptions are included in Appendix 5 to help illustrate the themes and sub-themes.

Lack of access to health care in ranchers contained both external factors (distance, cost) and internal factors (a culture of toughness in ranching, time pressures of ranching, and skepticism about the value of visiting a physician). Ranchers, especially female ranchers, expressed that physicians do not take their pain seriously and did not appreciate the physical demands of ranching. Because of its long recovery period and the impact on ranch work ("...that's going to put me out of business for 4 to 6 months"), joint replacement is often delayed until disability is severe, resulting in ranchers working in pain for many years. Treatment recommendations are often not followed because of the demands of ranching ("...the sling only stayed on one day", "...you don't follow up with physical therapy afterwards, because you're so darn busy."), and follow-up visits may not occur because of time constraints, distance and cost. Ranchers 
also expressed that they are working into older age and may not have the help of their grown children, who are more apt lately to find occupations outside of agriculture ("...you used to have a pile of kids (to help)."), and that hired help is difficult to find in rural areas.

\section{Discussion}

\section{Joint Health and Economic Health in Agriculture}

A principal aim of this study was to assess the effects of joint pain and arthritis on the economics of farming and ranching. For those with hip or knee pain, we found higher WOMAC scores to be negatively associated with a farm or ranch's financial well-being, with every 10-point increase in WOMAC score increasing the odds of self-reporting the next worse financial category by a factor of 1.23 . When a ranch or farm is operated by only a small number of persons, such as in our study (mean $=2.8$ ) and that of McMillan et al $(73 \%$ of farms had $1-2$ workers), $(8,20)$ the physical disability of one person is apt to cause decreased productivity, which may lead to economic hardship. Indeed, for every 10-point increase in WOMAC in our study, the odds of moving to the next worse quartile of work capacity increased by a factor of 2.0 , and odds of needing to rely on others to perform one's work increased by a factor of 1.8 .

For all types of agricultural commodities, having a diagnosis of arthritis or OA was similarly associated with lowered work capacity, and an arthritis diagnosis was associated with increased reliance on others. These findings are consistent with prior studies and provide further evidence of an association between arthritis and reduced work capacity in farmers/ranchers. $(3,20)$ With regard to ranchers as a subset of ag producers, our focus group results illuminate the importance of this association. The combination of the younger generation moving on to other occupations, a small number of workers on each farm or ranch, difficulty in hiring help, barriers to accessing medical care, and the effects of joint pain on productivity, produces a situation in which the physical demands of ranch work are unrelenting, but ranchers become progressively physically unable to meet those demands. This is concerning, with regard to their economic well-being and our reliance on the ag commodities that ranchers produce.

Our study found no association between diagnosed arthritis or $\mathrm{OA}$ and the self-reported economic condition of the ranch or farm, but these self reports may have been unreliable. A literature review on the determinants of social desirability bias in surveys found income to be a particularly sensitive survey topic due to the social context of the question.(21) Two recent studies comparing differences in self-reported and actual income found strong evidence for social desirability bias in self-reported income, resulting in inflated values. $(22,23)$ We were told by MSU Extension agents that farmers and ranchers were unlikely to provide accurate responses to questions about financial health. Therefore, we relied more on the surrogate indicators of reduced work capacity and the need to rely on others to perform work.

Of those diagnosed with arthritis in our study, 35.3\% were unsure of the type, and many likely had OA, it being the most common arthritis type in the United States, with $12.1 \%$ of adults meeting diagnostic criteria.(24) When calculating associations between OA diagnosis and economic hardship outcomes, 
those with diagnosed OA were compared to those without, which included no arthritis diagnosis, those with other types of arthritis and those with arthritis but unsure of the type. This misclassification of cases likely weakened or nullified the true associations between OA and outcome variables in our study. Despite this, our study observed a significant association between having OA diagnosis and reduced work capacity. Complete inability to work was rare in our survey respondents, a phenomenon that was echoed in our focus groups and also shown in previous studies. $(25,26)$ This is likely attributable to the culture of toughness and qualities of perseverance demonstrated in our focus group themes.

\section{Arthritis Prevalence}

One of our study aims was to determine the prevalence of doctor-diagnosed arthritis and OA among Montana ag workers. However, our focus group results with ranchers highlighted barriers to accessing medical care in this population, which ranged from geographic and economic difficulties to outright avoidance ("What are they going to do?", "You just let it heal crooked."). As such, cases may be vastly under-reported due to these healthcare barriers contributing to under-diagnosis within the ag community. More research is needed to further explore the presence of these barriers and associated consequences within the broader ag community.

Arthritis prevalence in our study was higher than was seen in the Montana Behavioral Risk Factor Surveillance Survey (MT-BRFSS), which samples respondents randomly by phone.(27) Unadjusted for age, our study showed a higher arthritis prevalence in agricultural workers (47.0\% of respondents) than the MT-BRFSS (20.9\% of respondents). After age adjustment, using the age distribution of the Montana population, these values were $32.5 \%$ and $18.1 \%$, respectively. Selection bias in our study may have been encouraged by the inclusion of a cover letter sent with each survey or survey invitation that represented this project as a first step in an effort to improve arthritis care in the agricultural community, which may have attracted more respondents who have joint issues. The MT-BRFSS(27) showed ag workers to have a lower prevalence of arthritis than the general population (age-adjusted ag 18.1\%, non-ag 19.9\%), which disagrees with literature studies.(12-14) As with our survey, the MT-BRFSS inquired whether respondents had been diagnosed with arthritis by a health professional. These findings do not account for those who have arthritis but have not been diagnosed, and considering the common avoidance of medical care expressed by ranchers in our study, may disproportionately under-estimate the true prevalence of arthritis in this population.

The mean age of ranchers and farmers in our survey was higher than that obtained in MT-BRFSS (59.3 years, S. D. 14.3 and 49.9 years, S. D. 16.7, respectively).(27) The majority of our surveys were conducted in paper format in Custer, Granite and Liberty counties. For Custer and Granite, two surveys were included in each mailing, and the mean ages for survey respondents in those counties were 65.0 and 62.7, respectively. To test whether we were only obtaining surveys completed by the oldest workers (e.g., the parents) on the ranch or farm, when perhaps their grown children may still work the farm but live separately, we included five surveys in each paper survey mailing for Liberty County. These surveys were 
marked in a fashion that maintained confidentiality but allowed grouping of surveys from each individual farm or ranch. Using the reported number of workers on a farm/ranch, when all workers from a farm/ranch submitted a survey, the mean age was 51.7, close to that of the MT-BRFSS cohort. In comparison when not all workers completed surveys on a given farm/ranch in Liberty County, the mean age was 60.8. This difference was statistically significant $(p<0.01)$. The inclusion of only two surveys per mailing in Custer and Granite Counties likely selected for an older working population, explaining most of the age difference when compared to MT-BRFSS.

We found an association between cumulative years working in agriculture and joint pain and a diagnosis of arthritis, but after adjusting for age and BMI, this association disappeared (Table 2).. This was unexpected, as time spent working in a high physical workload occupation has been shown in other studies to be an independent predictor of hip or knee osteoarthritis $(12,28)$ or total hip or knee arthroplasty.(13) In our focus groups, participants expressed that agriculture is a lifelong occupation ("Born and raised on a farm and ranch and done that pretty much all my life."), which would create a close association between age and years spent in agricultural work. Our survey results show a mean respondent age of 59.3 and a mean of 37.6 years spent working in agriculture, indicating that most of our respondents had spent their adult years on a ranch or farm. Our inability to detect an association between years working and joint health may be explained by the highly colinear relationship between age and years working in our sample, resulting in type 2 error.

\section{Conclusions}

For Montana ranchers and farmers, this mixed methods study demonstrated a statistically-significant association, but not causality, between having a diagnosis of arthritis or OA or a worsening WOMAC score and factors that may indicate economic risk to an agricultural operation. Our survey respondents demonstrated a reduced work capacity and a need to rely on others to complete agricultural tasks in the presence of worsening knee or hip symptoms (WOMAC score) or a diagnosis of arthritis or OA. Ranchers in our focus groups described a culture of toughness and working through pain, along with avoidance of medical care. Coupled with the younger generation seeking employment outside of agriculture, this leaves an older population struggling to maintain ranch and farm productivity in the presence of musculoskeletal disability. More effective treatment strategies for this population are therefore needed, tailored to the needs of the agricultural community and the nature of their daily work.

\section{List Of Abbreviations}

OA: osteoarthritis

MSU: Montana State University

OR: odds ratio

REDCap: Research Electronic Data Capture 
WOMAC: Western Ontario and McMaster University osteoarthritis index

MT-BRFSS: Montana Behavioral Risk Factor Surveillance Survey

ag: agriculture or agricultural

\section{Declarations}

\section{Ethics approval and consent to participate}

This study was deemed exempt by the Montana State University Institutional Review Board (MSU IRB), reference \# EA 100917-EX. All survey participants and focus group participants signed a consent form approved by the MSU IRB).

\section{Consent for publication}

Not applicable.

\section{Availability of data and materials}

The datasets supporting the conclusions of this article are available at the Dryad repository,

\section{https://doi.org/10.5061/dryad.0p2ngf1wm}

\section{Competing Interests}

Eliza M Webber-no competing interests

Tan Tran-no recompeting interests

Ronald June-reviewer/referee, Arthritis Research and Therapy

Emily Healy-no competing interests

Tara Andrews-no competing interests

Roubie Younkin-no competing interests

Justin MacDonald-no competing interests

Erik S Adams-no competing interests 


\section{Funding}

Research reported in this publication was supported by the National Institute of General Medical Sciences of the National Institutes of Health under Award Number P20GM103474. The content is solely the responsibility of the authors and does not necessarily represent the official views of the National Institutes of Health.

\section{Authors' Contributions}

Eliza Webber MPH-statistics, data analysis and interpretation, drafting of the article, review of final manuscript

Tan Tran PhD-statistics, data analysis and interpretation, review of final manuscript.

Ronald June PhD-study concept, statistical expertise, review of final manuscript.

Emily Healy MS-MT-BRFSS data, statistics, review of final manuscript.

Tara Andrews, MS-subject recruitment, creation of focus group, review of final manuscript.

Roubie Younkin, MEd-subject recruitment, creation of focus group, review of final manuscript.

Justin MacDonald, BS-data input and analysis, review of final manuscript

Erik Adams MD, PhD-principal investigator, data acquisition, analysis and interpretation, draft of the article, obtained funding, takes responsibility for the integrity of the work as a whole.

\section{Acknowledgements}

The authors gratefully acknowledge the assistance of the following persons: Megan Higgs, PhD, Wyatt Madden, Michaela Powell, and Allison Theobold, MS for statistics work. Montana State University Extension agents Josh Bilbao (Gallatin County), Ben Hauptman (Granite County), Katie Hatlelid (Judith Basin County), Jesse Fulbright (Liberty County), Tracy Mosley and Mary Anne Keyes (Park County), Julie Riley and Mary Rumph (Powder River County), Tim Fine and Carrie Krug (Richland County), and Western Region MSU Extension director Dan Lucas. Thank you to Colter Ellis, PhD and Sandra Bailey, PhD for helpful discussions and guidance.

\section{Authors' Information}

EJW: Research Project Manager, Center for American Indian and Rural Health Equity, Montana State University, Bozeman, MT. 
TT: Statistician with experience working as a consultant and data scientist. His research has focused on modeling and statistical learning, especially cluster analysis.

RJ: Associate Professor, Montana State University, Bozeman, MT. Arthritis metabolomics and articular cartilage researcher.

EH: Epidemiologist, Montana Department of Labor and Industry.

TMA: MSU Extension agent, Custer County, MT.

RY: MSU Extension agent, Valley County, MT.

JM: Medical student, University of Washington School of Medicine, WWAMI program.

ESA: Assistant research professor, Montana State University, Bozeman, MT. Member of the Dr. Ron June lab, MSU. Board-certified sports medicine physician, private practice in Bozeman, MT.

\section{References}

1.Cross M, Smith E, Hoy D, Nolte S, Ackerman I, Fransen M, et al. The global burden of hip and knee osteoarthritis: estimates from the global burden of disease 2010 study. Annals of the rheumatic diseases. 2014;73(7):1323-30.

2.Theis KA, Roblin DW, Helmick CG, Luo R. Prevalence and causes of work disability among working-age US adults, 2011-2013, NHIS. Disability and health journal. 2018;11(1):108-15.

3.Whelan S, Ruane DJ, McNamara J, Kinsella A, McNamara A. Disability on Irish farms-a real concern. Journal of agromedicine. 2009;14(2):157-63.

4.Barbour KE, Helmick CG, Boring M, Brady TJ. Vital signs: prevalence of doctor-diagnosed arthritis and arthritis-attributable activity limitation-United States, 2013-2015. MMWR Morbidity and mortality weekly report. 2017;66(9):246.

5.Holmberg S, Thelin A, Thelin N. Is there an increased risk of knee osteoarthritis among farmers? A population-based case-control study. International archives of occupational and environmental health. 2004;77(5):345-50.

6.Kirkhorn S, Greenlee RT, Reeser JC. The epidemiology of agriculture-related osteoarthritis and its impact on occupational disability. Wisconsin Medical Journal. 2003;102(7):38-44.

7.Tüchsen F, Hannerz H, Jensen M, Krause N. Socioeconomic status, occupation, and risk of hospitalisation due to coxarthrosis in Denmark 1981-99. Annals of the rheumatic diseases. 2003;62(11):1100-5. 
8.McMillan M, Trask C, Dosman J, Hagel L, Pickett W, Team SFICS. Prevalence of musculoskeletal disorders among Saskatchewan farmers. Journal of agromedicine. 2015;20(3):292-301.

9.Rubak TS, Svendsen SW, Søballe K, Frost P. Risk and rate advancement periods of total hip replacement due to primary osteoarthritis in relation to cumulative physical workload. Scandinavian journal of work, environment \& health. 2013:486-94.

10.Seidler A, Lüben L, Hegewald J, Bolm-Audorff U, Bergmann A, Liebers F, et al. Dose-response relationship between cumulative physical workload and osteoarthritis of the hip-a meta-analysis applying an external reference population for exposure assignment. BMC musculoskeletal disorders. 2018;19(1):182.

11.Solovieva S, Kontio T, Viikari-Juntura E. Occupation, Physical Workload Factors, and Disability Retirement as a Result of Hip Osteoarthritis in Finland, 2005-2013. The Journal of rheumatology. 2018;45(4):555-62.

12.Vingård E, ALFREDSSON L, Goldie I, HOGSTEDT C. Occupation and osteoarthrosis of the hip and knee: a register-based cohort study. International journal of epidemiology. 1991;20(4):1025-31.

13.Franklin J, Ingvarsson T, Englund M, Lohmander S. Association between occupation and knee and hip replacement due to osteoarthritis: a case-control study. Arthritis research \& therapy. 2010;12(3):R102.

14.Thelin A, Holmberg S. Hip osteoarthritis in a rural male population: A prospective population-based register study. American journal of industrial medicine. 2007;50(8):604-7.

15.Goekoop R, Kloppenburg M, Kroon H, Dirkse L, Huizinga T, Westendorp R, et al. Determinants of absence of osteoarthritis in old age. Scandinavian journal of rheumatology. 2011;40(1):68-73.

16.Extension MSU. 2019 Legislative Report. 2019.

17. Harris PA, Taylor R, Thielke R, Payne J, Gonzalez N, Conde JG. Research electronic data capture (REDCap)-a metadata-driven methodology and workflow process for providing translational research informatics support. Journal of biomedical informatics. 2009;42(2):377-81.

18. Harris PA, Taylor R, Minor BL, Elliott V, Fernandez M, O'Neal L, et al. The REDCap consortium: Building an international community of software platform partners. Journal of biomedical informatics. 2019;95:103208.

19.McCullagh P. Regression Models for Ordinal Data. Journal of the Royal Statistical Society: Series B (Methodological). 1980;42(2):109-27.

20.Taylor-Gjevre RM, Trask C, King N, Koehncke N, Team SFICS. Prevalence and occupational impact of arthritis in Saskatchewan farmers. Journal of agromedicine. 2015;20(2):205-16. 
21.Krumpal I. Determinants of social desirability bias in sensitive surveys: a literature review. Quality \& Quantity. 2013;47(4):2025-47.

22.Angel S, Disslbacher F, Humer S, Schnetzer M. What did you really earn last year?: explaining measurement error in survey income data. Journal of the Royal Statistical Society: Series A (Statistics in Society). 2019.

23.Hariri JG, Lassen DD. Income and outcomes Social desirability bias distorts measurements of the relationship between income and political behavior. Public Opinion Quarterly. 2017;81(2):564-76.

24.Lawrence RC, Felson DT, Helmick CG, Arnold LM, Choi H, Deyo RA, et al. Estimates of the prevalence of arthritis and other rheumatic conditions in the United States: Part II. Arthritis \& Rheumatism. 2008;58(1):26-35.

25.Caban-Martinez AJ, Lee DJ, Fleming LE, Tancredi DJ, Arheart KL, LeBlanc WG, et al. Arthritis, occupational class, and the aging US workforce. American journal of public health. 2011;101(9):172934.

26.Coggon D, Croft P, Kellingray S, Barrett D, McLaren M, Cooper C. Occupational physical activities and osteoarthritis of the knee. Arthritis \& Rheumatism: Official Journal of the American College of Rheumatology. 2000;43(7):1443-9.

27.BRFSS. Montana Behavioral Risk Factor Surveillance Survey In: System BRFS, editor.: Behavioral Risk Factor Surveillance System Office, Montana Department of Public Health and Human Services; 2017.

28.Andersen S, Thygesen LC, Davidsen M, Helweg-Larsen K. Cumulative years in occupation and the risk of hip or knee osteoarthritis in men and women: a register-based follow-up study. Occup Environ Med. 2012;69(5):325-30.

\section{Tables}

Due to technical limitations, Tables 1 - 3 are only available for download from the Supplementary Files section.

\section{Figures}




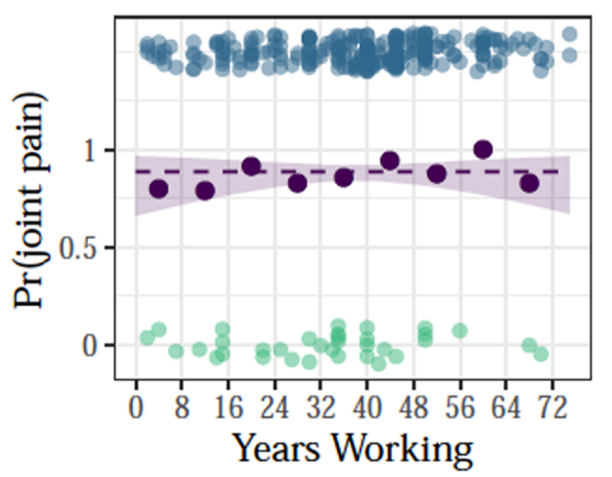

A



B

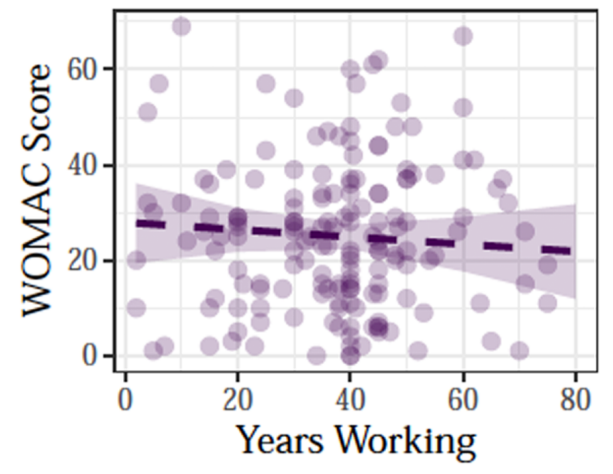

C

\section{Figure 1}

After adjusting for age and BMI, no evidence of association was observed between number of years working on a farm/ranch and the following joint health outcomes: presence of joint pain (OR 1.00; $95 \% \mathrm{Cl}$ $[0.70,1.42], p=0.99$ ), arthritis diagnosis (OR 0.99; $95 \% \mathrm{Cl}[0.79,1.24], \mathrm{p}=0.93$ ), OA diagnosis (OR $0.83 ; 95 \%$ $\mathrm{Cl}[0.64,1.07], p=0.28$ ) and WOMAC score (mean difference: $-0.38 ; 95 \% \mathrm{Cl}[-2.41,1.65], p=0.71$ ) per 10-unit increase in years working (Table 2 and Figure $1 \mathrm{~A}-\mathrm{C}$ ).

\section{Supplementary Files}

This is a list of supplementary files associated with this preprint. Click to download.

- WebberetalTables13.docx

- WebberetalAppendices15.docx 